University of Nebraska - Lincoln

DigitalCommons@University of Nebraska - Lincoln

\title{
Variant high-molecular-weight glutenin subunits arising from biolistic transformation of wheat
}

Ann E. Blechl

USDA-ARS, ann.blechl@ars.usda.gov

William $\mathrm{H}$. Vensel

USDA-ARS

Follow this and additional works at: https://digitalcommons.unl.edu/usdaarsfacpub

Blechl, Ann E. and Vensel, William H., "Variant high-molecular-weight glutenin subunits arising from biolistic transformation of wheat" (2013). Publications from USDA-ARS / UNL Faculty. 1143.

https://digitalcommons.unl.edu/usdaarsfacpub/1143

This Article is brought to you for free and open access by the U.S. Department of Agriculture: Agricultural Research Service, Lincoln, Nebraska at DigitalCommons@University of Nebraska - Lincoln. It has been accepted for inclusion in Publications from USDA-ARS / UNL Faculty by an authorized administrator of DigitalCommons@University of Nebraska - Lincoln. 


\title{
Variant high-molecular-weight glutenin subunits arising from biolistic transformation of wheat
}

\author{
Ann E. Blech"*, William H. Vensel \\ USDA - ARS, Western Regional Research Center, 800 Buchanan St., Albany, CA 94710-1105, USA
}

\section{A R T I C L E I N F O}

\section{Article history:}

Received 1 October 2012

Received in revised form

15 February 2013

Accepted 18 February 2013

\section{Keywords:}

Transgenic

$1 \mathrm{Dx} 5$

1 Dy 10

Tandem mass spectrometry

\begin{abstract}
A B S T R A C T
Genetic transformation via the biolistic method has been used to introduce genes encoding natural and novel high-molecular-weight glutenin subunits (HMW-GS) into wheat. The appearance of new seed proteins of sizes not predicted by the transgene coding sequences was noted in some experiments. In this report, the identities of thirteen of these novel proteins were determined by tandem mass spectrometry (MS/MS). Seven different proteins larger than and two proteins smaller than the native protein were shown to contain peptides from $1 \mathrm{Dx} 5$. A novel protein found in some progeny of crosses between a transgenic plant and Great Plains winter wheats was larger than but contained several peptides from 1Dy10. In one line, a protein larger than and a protein smaller than HMW-GS each contained peptides from the $\mathrm{N}$ - and $\mathrm{C}$-terminus of $1 \mathrm{Dx} 5$ and from the repeat region of $1 \mathrm{Dy} 10$. In a sixth transgenic line, the native $B \times 7$ gene was apparently replaced by a gene that encodes a larger version of $1 \mathrm{Bx} 7$. The variant proteins accumulate in the polymeric protein fraction, indicating that they can form inter-molecular disulfide bonds. These results show that novel proteins found in some transformants are encoded by altered versions of either the transforming or endogenous HMW-GS genes.
\end{abstract}

Published by Elsevier Ltd.

\section{Introduction}

Genetic transformation is one of several approaches used to understand the contributions of individual genes and seed proteins to wheat (Triticum aestivum) end-use functionality. The moststudied wheat quality genes are those encoding high-molecularweight glutenin subunits (HMW-GS), which typically constitute $5-10 \%$ of seed storage proteins and are important determinants of dough strength and elasticity (reviewed and referenced in Shewry et al., 2003). Addition of native or modified HMW-GS genes to wheat generally results in accumulation of proteins of the expected sizes in addition to those encoded by the native genes (Altpeter et al., 1996; Alvarez et al., 2000; Barro et al., 1997; Blechl and Anderson, 1996; He et al., 1999, 2005; León et al., 2009). Transformants carrying expressed transgenes encoding native HMW-GS produce flours that make doughs with increased mixing times and tolerances compared to their non-transformed parent lines (Alvarez et al., 2001; Barro et al., 1997, 2003; Blechl et al., 2007; Darlington et al., 2003; He et al., 1999; León et al., 2009; Popineau

Abbreviations: HMW-GS, high-molecular-weight glutenin subunits; MS/MS, tandem mass spectrometry; RP-HPLC, reverse-phase liquid chromatography.

* Corresponding author. Tel.: +1 510559 5716; fax: +1 5105595818.

E-mail address: ann.blechl@ars.usda.gov (A.E. Blechl). et al., 2001; Rakszegi et al., 2005; Rooke et al., 1999; Vasil et al., 2001). However, some HMW-GS gene transformation events contain proteins of unpredicted sizes in addition to or instead of those encoded by the introduced transgenes (Altpeter et al., 1996: Alvarez et al., 2000; Barro et al., 1997; Blechl and Lin, 2007; He et al., 2005). In this report, we characterize thirteen of these proteins by tandem mass spectrometry (MS/MS) and show that they are size variants of HMW-GS.

\section{Materials and methods}

\subsection{Derivation of transformed lines}

The transformation events characterized here were produced in the same experiments as those described previously (Blechl et al., 2007). Briefly, cultivar 'Bobwhite' was co-transformed with the Ubi::BAR selection plasmid and separate DNA plasmids carrying the wheat genomic EcoR1 fragments from cultivar 'Cheyenne' that encode either 1Dx5 or 1Dy10 (Anderson et al., 1989). After selection with bialaphos, putative transformants were identified by changes in the levels of $1 \mathrm{Dx} 5$ and/or Dy 10 in $\mathrm{T}_{1}$ seeds. Homozygous progeny from each event were identified by SDS-PAGE of seed proteins and used to establish true-breeding lines (Blechl et al., 2007). Lines were named by the introduced HMW-GS gene(s), e.g., Dx5 + Dy10, followed by a unique event letter. 
An additional event "B52a-6" was characterized after the transgene had been crossed into hard winter wheat lines. The derivation and characterization of those lines are described in Graybosch et al. (2011). The original 'Bobwhite' transformant was co-transformed by Ubi::BAR and a plasmid carrying the native gene encoding 1Dy10.

\subsection{Protein characterization}

\subsubsection{Mass spectrometry}

To prepare individual protein bands for mass spectrometry, SDSPAGE was performed as described previously (Blechl and Anderson, 1996 for Fig. 1C; Blechl et al., 2007 for Figs. 1A, B, D and 3). In some experiments, proteins were reduced and then alkylated by incubation for $30 \mathrm{~min}$ at room temperature in $4 \%(\mathrm{w} / \mathrm{v})$ iodoactamide, $50 \mathrm{mM}$ Tris- $\mathrm{HCl}$ (pH 8.8), 2\% (w/v) SDS before loading onto the gels (method adapted from Görg et al., 2004). Bands corresponding to novel proteins were excised from the gels and placed into the reaction plate of a DigestPro (Itavis, Koeln, DE), where the proteincontaining spots were destained, reduced, alkylated, and digested with trypsin. The resulting tryptic peptides were automatically eluted into a 96-well plate in preparation for LC-MS/MS.

Identification of protein-containing bands was carried out as previously described (Vensel et al., 2005). The 96-well collection plate from the DigestPro was inserted into the autosampler of the Reverse-Phase (RP)-HPLC system that was interfaced to a QSTAR PULSAR $i$ quadrupole time-of-flight mass spectrometer (Applied Biosystems/MDS Sciex, Toronto, CA). Conditions for operation of the instrument were as previously described (Vensel et al., 2005). A minimum of four independent samples for each protein variant were excised from gels and analyzed.

\subsubsection{Protein identification}

Extraction of peak lists from the QSTAR Analyst QS wiff files and their conversion to text files was carried out using Mascot Daemon (http://www.matrixscience.com/). MS/MS samples were analyzed using Mascot (Matrix Science, London, UK; version 2.1.04) and X! Tandem (www.thegpm.org; version 2006.04.01.2). Mascot was set up to search a specially constructed database with all Triticae sequences (as of January 2009) and the protein sequences of Phosphinothricin Acetyl Transferase (Accession No. P16426 encoded by the BAR gene), beta lactamase (Accession No. AAB59737.1 encoded by the bla1 gene for ampicillin resistance), and $\beta$-galactosidase
(Accession No. P00722 encoded by the lacZ gene). The specified digestion enzyme was trypsin. Using the post-analysis software package Mascot and X! Tandem (Craig and Beavis, 2004), results were searched with a fragment ion mass tolerance of $1.00 \mathrm{Da}$ and a parent ion tolerance of $1.00 \mathrm{Da}$. Iodoacetamide derivative of cysteine was specified in Mascot and X! Tandem as a fixed modification while oxidation of methionine and deamidation at $\mathrm{N}$ and $\mathrm{Q}$ were specified as variable modifications.

Validations of tandem MS-based peptide and protein identifications were performed using Scaffold (Scaffold version 2.06.01, Proteome Software Inc., Portland, OR). Protein probabilities were assigned by the Protein Prophet algorithm (Keller et al., 2002; Nesvizhskii et al., 2003). The protein identifications reported in Table 1 were established at $100.0 \%$ probability and contain at least 2 peptides identified with greater than $90 \%$ probability.

\subsubsection{Protein solubility}

Whole seeds homozygous for the transgenes were ground and extracted three times with 50\% propanol. The residue was dissolved in SDS-PAGE sample buffer containing 2-mercaptoethanol and loaded onto $4-12 \%$ gradient gels for electrophoresis (Blechl et al., 2007).

\section{Results}

Previously we reported the generation of multiple independent transformation events obtained by particle bombardment with the Ubi::BAR selection gene and plasmids containing the native genes encoding HMW-GS 1Dx5 and/or 1Dy10 (Blechl et al., 2007). Analyses by SDS-PAGE of seed proteins showed that 23 of 30 transformants had an increase in the protein band(s) corresponding to HMW-GS 1Dx5 and/or 1Dy10, as expected (open circles in Fig. 1), while the other seven exhibited transgene-mediated co-suppression (Blechl and Lin, 2007; lane 2 of Fig. 1B). However, seven of the events with increased expression of 1Dx5 and/or 1Dy10 also contained one or more novel protein bands (arrowheads in lanes 1, $3-7,9,11$, and 12 of Fig. 1). Most of the novel proteins were of higher molecular weight than native HMW-GS, although lower molecular-weight bands were also apparent in three transformants (lanes 1, 3 and 4, Fig. 1). Among 13 transformants with the $1 D x 5$ gene, we observed three lines with variant proteins. Among 10 transformants with both $1 D x 5$ and 1Dy 10 genes, we observed four such lines (Blechl and Lin, 2007). Among 7 lines transformed with
A

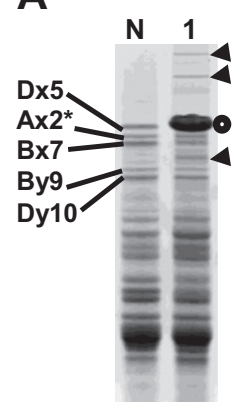

B

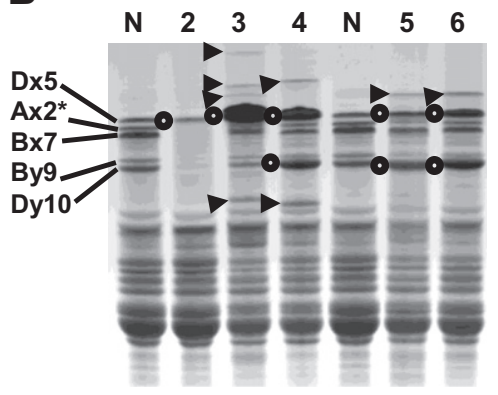

C

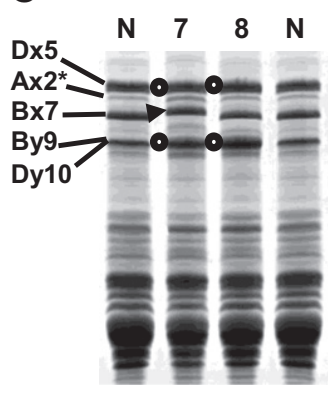

D

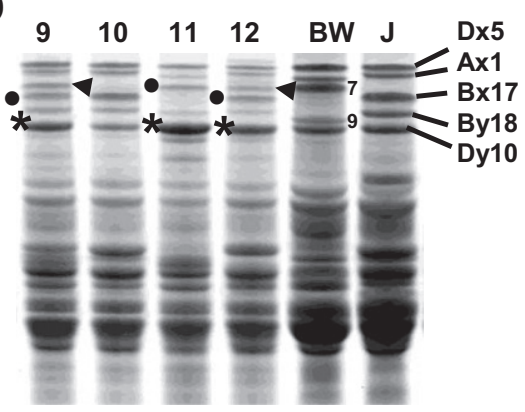

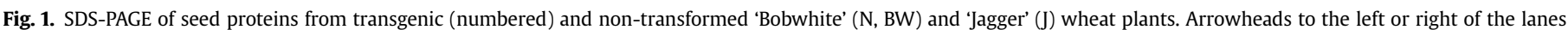

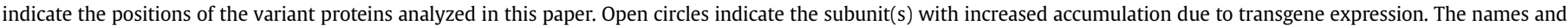

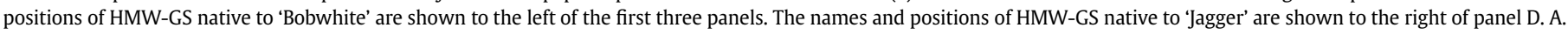

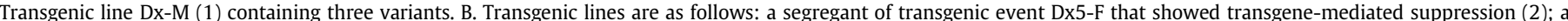

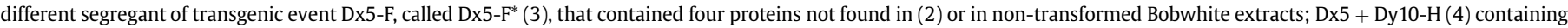

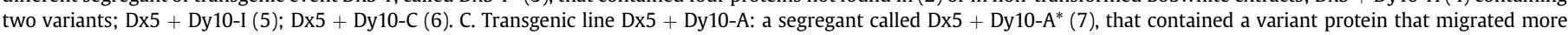

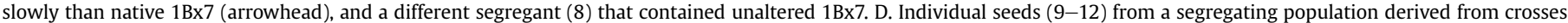

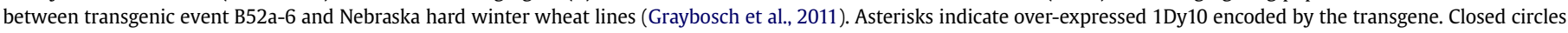
indicate other HMW-GS identified by tandem MS. The positions of subunits 1Bx7 (7) and 1By9 (9) are indicated to the right of the BW lane. 
Table 1

Protein and peptide identities for variants in transgenic wheat lines.

\begin{tabular}{|c|c|c|c|c|}
\hline $\begin{array}{l}\text { Transgenic event } \\
\text { [figure, gel lane] } \\
\text { variant band }\end{array}$ & $\begin{array}{l}\text { Number of independent } \\
\text { samples with identified } \\
\text { proteins }\end{array}$ & $\begin{array}{l}\text { Proteins identified } \\
\text { with } 100 \% \text { probability } \\
\text { (\# samples) }\end{array}$ & $\begin{array}{l}\text { Average \% of protein } \\
\text { covered by detected } \\
\text { peptides }\end{array}$ & $\begin{array}{l}\text { Peptides identified } \\
\text { by Scaffold with probabilities } \\
\text { of } 90 \% \text { or higher (\# samples) }\end{array}$ \\
\hline \multirow[t]{2}{*}{ Dx5-M [Fig. 1A, 1] largest } & \multirow[t]{2}{*}{7 alkylated } & $1 \mathrm{Dx} 5(7)$ & 4.5 & $2(2), 5(7), 6(5),{ }^{*} 10(3), 12(2)$ \\
\hline & & Sucrose synthase I (2) & 2 & Two unique \\
\hline \multirow{2}{*}{$\begin{array}{l}\text { Dx5-M [Fig. 1A, 1] } \\
\text { 2nd largest }\end{array}$} & \multirow[t]{2}{*}{7 alkylated } & $1 \mathrm{Dx} 5(7)$ & 5 & $2(5), 5(5), 6(5),{ }^{*} 10(4), 11(1), 12(5)$ \\
\hline & & Sucrose synthase I (3) & 3.5 & Two or three unique \\
\hline \multirow[t]{3}{*}{$\begin{array}{l}\text { Dx5-M [Fig. 1A, 1] between } \\
\text { native } 1 \mathrm{Bx} 7 \text { and } 1 \mathrm{By} 9\end{array}$} & \multirow[t]{3}{*}{8 alkylated } & $1 \mathrm{Dx} 5(8)$ & 7 & $\begin{array}{l}2(6), 3(1), 4(1), 5(8), 6(8), 8 \text { frag }(1),{ }^{*} 10(3), \\
11(2), 12(7)\end{array}$ \\
\hline & & Sucrose synthase I (4) & 22 & Eleven to eighteen unique \\
\hline & & Sucrose synthase II (4) & 12.5 & Two to seven unique \\
\hline \multirow[t]{2}{*}{ Dx5-F* [Fig. 1B, 3] largest } & 6 non-alkylated & $1 \mathrm{Dx} 5(6)$ & 7.5 & $1(5), 2(4), 3(6), 4(1), 5(5), 6(3), 11(4), 12(3)$ \\
\hline & 2 alkylated & $1 \mathrm{Dx} 5(2)$ & 3 & $5(2), 6(2)$ \\
\hline Dx5-F* [Fig. 1B, 3] & 7 non-alkylated & $1 \mathrm{Dx} 5(7)$ & 10 & $1(7), 2(6), 3(7), 4(3), 5(7), 6(4), 11(5), 12(4)$ \\
\hline 2nd largest & 3 alkylated & $1 \mathrm{Dx} 5(3)$ & 4 & $2(2), 5(3), 6(2),{ }^{*} 10(1)$ \\
\hline Dx5-F* [Fig. 1B, 3] & 4 non-alkylated & $1 \mathrm{Dx} 5(4)$ & 9 & $1(3), 2(2), 3(4), 5(4), 6(4), 11(4), 12(2)$ \\
\hline 3rd largest & 4 alkylated & $1 \mathrm{Dx} 5(4)$ & 4.5 & $2(2), 5(4), 6(4),{ }^{*} 10(1), 12(1)$ \\
\hline \multirow{7}{*}{$\begin{array}{l}\text { Dx5-F* [Fig. 1B, 3] } \\
\text { smallest }\end{array}$} & \multirow[t]{3}{*}{8 non-alkylated } & $1 \mathrm{Dx} 5(8)$ & 10 & $1(8), 2(7), 3(8), 4(4), 5(8), 6(7), 11(4), 12(3)$ \\
\hline & & $\begin{array}{l}\text { Protein disulfide } \\
\text { isomerases (5) }\end{array}$ & 28 & Two to eighteen unique \\
\hline & & Globulin $3(4)$ & 23 & Nine or ten unique \\
\hline & \multirow[t]{4}{*}{8 alkylated } & $1 \mathrm{Dx} 5(7)$ & 3 & $5(7), 6(7), 12(1)$ \\
\hline & & Globulin $3(8)$ & 39.5 & Fourteen to twenty-six unique \\
\hline & & Phosphoglucomutase (1) & 4 & Two unique \\
\hline & & Unknown $60 \mathrm{kDa}(1)$ & 7 & Two unique \\
\hline \multirow{4}{*}{$\begin{array}{l}\text { Dx5 + Dy10-H [Fig. 1B, 4] } \\
\quad \text { larger }\end{array}$} & \multirow[t]{2}{*}{4 non-alkylated } & $1 \mathrm{Dx} 5(4)$ & 7.5 & $1(4), 2(2), 3(3), 5(4), 6(4), 11(1), 12(1)$ \\
\hline & & $1 \mathrm{Dy} 10(4)$ & 4 & $26(1), 38(3), 39(4)$ \\
\hline & \multirow[t]{2}{*}{8 alkylated } & $1 \mathrm{Dx} 5(8)$ & 4.5 & $2(1), 3(3), 5(8), 6(8)$ \\
\hline & & $1 \mathrm{Dy} 10(1)$ & 7 & *37 (1), $38(1)$ \\
\hline \multirow{5}{*}{$\begin{array}{l}\text { Dx5 + Dy10-H [Fig. 1B, 4] } \\
\text { smaller }\end{array}$} & \multirow[t]{2}{*}{4 non-alkylated } & $1 \mathrm{Dx} 5(4)$ & 10.5 & $1(4), 2(4), 3(4), 4(1), 5(4), 6(4), 11(4), 12(3)$ \\
\hline & & $1 \mathrm{Dy} 10(2)$ & 2 & Two versions of $38(2)$ \\
\hline & \multirow[t]{3}{*}{8 alkylated } & $1 \mathrm{Dx} 5(8)$ & 10.5 & $2(8), 3(8), 4(5), 5(8), 6(7),{ }^{*} 10(6), 11(1), 12(8)$ \\
\hline & & $1 \mathrm{Dy} 10(5)$ & 4.5 & *37 (2), frag *37 (3), $38(5)$ \\
\hline & & Globulin $3(8)$ & 20 & Four to ten unique \\
\hline \multirow{2}{*}{$\begin{array}{l}\text { Dx5 + Dy10-I [Fig. 1B, 5] } \\
\text { large }\end{array}$} & 4 non-alkylated & $1 \mathrm{Dx} 5(4)$ & 9 & $1(4), 2(3), 3(4), 5(4), 6(4), 11(3), 12(2)$ \\
\hline & 4 alkylated & $1 \mathrm{Dx} 5(4)$ & 9.5 & $2(4), 3(4), 5(4), 6(4),{ }^{*} 10(4), 11(2), 12(4)$ \\
\hline \multirow[t]{4}{*}{ Dx5 + Dy10-C [Fig. 1B, 6] } & \multirow[t]{3}{*}{7 non-alkylated } & $1 \mathrm{Dx} 5(7)$ & 14.5 & $\begin{array}{l}1(7), 2(7), 3(7), 4(7), 5(7), 6(7), 7(1), 8(2), \\
11(6), 12(6)\end{array}$ \\
\hline & & $1 \mathrm{Dy} 10(6)$ & 8 & $\begin{array}{l}25(1), 26(5), 27(3), 30(2), 32(1), 33(2) \\
\text { fragment } 34(1), 35(1), 39(4)\end{array}$ \\
\hline & & $1 \mathrm{Bx} 7(4)$ & 6.5 & $14+15(4), 15(1), 16(4), 18(1), 11(4)$ \\
\hline & 7 alkylated & $1 \mathrm{Dx} 5(7)$ & 10 & $\begin{array}{l}2(7), 3(5), 4(2), 5(7), 6(7), \text { frag } 8(1),{ }^{*} 10(7), \\
11(3), 12(7)\end{array}$ \\
\hline \multirow[t]{6}{*}{ Dx5 + Dy10-A* [Fig. 1C, 7] } & 4 non-alkylated & $1 \mathrm{Bx} 7(3)$ & 26.5 & $\begin{array}{l}13(3), 14+15(3), 16(2), 17(3), 18(2), 19(3) \\
20(2), 21(1),{ }^{*} 23(1), 24(2), 11(3)\end{array}$ \\
\hline & & $1 \mathrm{Ax} 2(2)$ & 13.5 & $\begin{array}{l}\text { Two or seven unique including one in N-terminus } \\
\text { (2) and six in repeats }\end{array}$ \\
\hline & & $1 \mathrm{Dx} 5(4)$ & 6.5 & $1(1), 2(1), 3(3), 4(1), 5(2), 6(4), 11(4)$ \\
\hline & & Sucrose synthase I (1) & 4 & Two unique \\
\hline & 4 alkylated & $1 \mathrm{Bx} 7(4)$ & 15 & $\begin{array}{l}14+15(2), 16(4), 17 \text { or fragment }(4), 19(2) \\
20(1), 21(4), 23(3), 24(4)\end{array}$ \\
\hline & & $1 \mathrm{Ax} 2^{*}(4)$ & 13 & $\begin{array}{l}\text { Three to eight unique including two in N-terminus } \\
\text { (2) and six in repeat regions (4) }\end{array}$ \\
\hline $\begin{array}{l}\text { Dy10 - B52a-6 [Fig. 1D, 9] } \\
\quad \text { Larger }\end{array}$ & 4 alkylated & $1 \mathrm{Bx} 7$ or $17(4)$ & 13.5 & $\begin{array}{l}14+15(1), 16(4), 17 \text { frag (2), } 19(1), 21(4) \\
{ }^{*} 22(1),{ }^{*} 23(4), 24(4)\end{array}$ \\
\hline & & $1 \mathrm{Ax} 2 *$ or $1 \mathrm{Ax} 1$ & 8 & $\begin{array}{l}\text { Two to six unique, including one in N-terminus } \\
\text { and five in repeat regions }\end{array}$ \\
\hline & & 1Dy10 (4) or 1By9 (2) & 4 & $26(4), 27(4), 30(2)$ \\
\hline & & $\begin{array}{l}\text { Unknown } 90 \mathrm{kDa} \\
\text { protein (1) }\end{array}$ & 4 & Two unique (1) \\
\hline & & Ortho dikinase (1) & 6 & Two unique (1) \\
\hline $\begin{array}{l}\text { Dy10 - B52a-6 [Fig. 1D, 9] } \\
\text { smaller }\end{array}$ & 4 alkylated & $1 \mathrm{Bx} 7$ or $1 \mathrm{Bx} 17(4)$ & 15.5 & $\begin{array}{l}14+15(4), 16(4), \text { frag } 17(2), 18(1), 19(2), \\
21(4),{ }^{*} 23(4), 24(4)\end{array}$ \\
\hline & & $1 \mathrm{Ax} 2^{*}$ or $1 \mathrm{Ax} 1(2)$ & 4.5 & Two unique in repeat region $(2)$ \\
\hline & & Sucrose synthase II (4) & 18 & Eight to fourteen unique \\
\hline & & Elongation factor (2) & 16 & Two unique \\
\hline Dy10 - B52a-6 [Fig. 1D, 11] & 4 alkylated & $1 \mathrm{Bx} 7$ or $1 \mathrm{Bx} 17(4)$ & 7.5 & $11(1), 16(4), 19(1), 21(1),{ }^{*} 23(4), 24(4)$ \\
\hline $\begin{array}{l}\text { Dy10 - B52a-6 [Fig. 1D, 12] } \\
\text { larger }\end{array}$ & 4 alkylated & $1 \mathrm{Dy} 10(4)$ & 10.5 & $\begin{array}{l}25(4), 26(3), 27(4), 30(4), 31(3), 32 \text { frag (3), } \\
38(3)\end{array}$ \\
\hline $\begin{array}{l}\text { Dy10 - B52a-6 [Fig. 1D, 12] } \\
\text { smaller }\end{array}$ & 4 alkylated & $\begin{array}{l}1 \mathrm{Bx} 7 \text { or } 1 \mathrm{Bx} 17(4) \\
\text { Sucrose synthase II (4) }\end{array}$ & $\begin{array}{l}8 \\
14.5\end{array}$ & $\begin{array}{l}16(4), 19(3),{ }^{*} 23(4), 24(4) \\
\text { Six to thirteen unique peptides }\end{array}$ \\
\hline
\end{tabular}

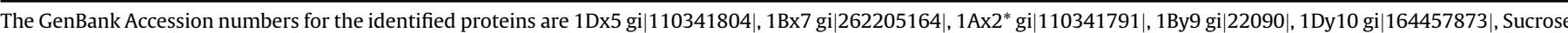

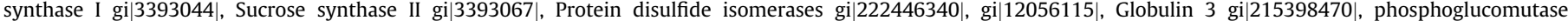

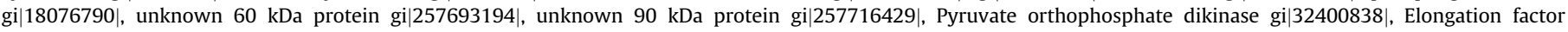
gi $\mid 58500286$.

The "Peptides Identified" in the last column of Table 1 are presented from Figure 2. 
only the $1 D y 10$ gene, we found one with an unexpected protein in the HMW-GS region of gels. This line was crossed with Great Plains winter wheats and further characterized in those backgrounds (Graybosch et al., 2011). Seeds from these derived lines can contain seed storage proteins other than those in the transformed cultivar 'Bobwhite' (BW in Fig. 1D), including HMW-GS 1Ax1, 1Bx17 and 1By18 found in winter wheat 'Jagger' (J in Fig. 1D). Protein extracts from four individual seeds of the derived lines are shown in lanes 9-12 of Fig. 1D.

In two events, we noted segregation of progeny with different seed protein patterns from a single regenerated transformed plant. One such event, Dx5-F, had some progeny seeds that exhibited transgene-mediated co-suppression (lane 2 of Fig. 1B) and other seeds (lane 3 of Fig. 1B) that showed increased accumulation of 1Dx5, some accumulation of the other HMW-GS, and four additional protein bands that were not present in either the suppressed segregant or in non-transformed 'Bobwhite' (lanes N of Fig. 1B). In the first generation progeny, we were able to select segregants with the different transgene expression patterns, which then bred true, producing homozygous progeny with the uniform seed protein compositions seen in lanes 2 and 3 of Fig. 1B. We designated the line with the variant bands Dx5- $F^{*}$. Another transgenic event, line Dx5 + Dy10-A, also produced two types of progeny with overexpression of $1 \mathrm{Dx} 5$ and $1 \mathrm{Dy} 10$ subunits. In some $\mathrm{T}_{1}$ seeds, the native $1 \mathrm{Bx} 7$ band was replaced by a protein of slightly slower mobility (Fig. 1C, compare lanes 7 and 8). The difference in migration was apparent in large $(15 \times 15 \mathrm{~cm}) 10 \%$ SDS-PAGE gels (Blechl and Anderson, 1996), but not in a smaller $(10 \times 10 \mathrm{~cm}) 4-$ $12 \%$ gradient gel format (Blechl et al., 2007). Homozygous lines with the native $1 \mathrm{Bx} 7$ or the variant protein were derived from the primary transformant. The line with the variant was called Dx5 + Dy10-A*.

The variant bands were excised from SDS-PAGE gels, digested with trypsin, and subjected to MS/MS. Fig. 2 shows the protein sequences of $1 \mathrm{Dx} 5$ (A), 1Bx7 (B) and 1Dy10 (C) with the locations of arginine (R), lysine $(K)$ and cysteine $(C)$ amino acids highlighted. The peptides that were actually identified by the MS/MS analyses reported here are assigned numbers. As expected for trypsin digestion, all the detected peptides ended in K or R. However, not all the peptides identified were directly preceded by $\mathrm{K}$ or R. The starts of those peptides are marked by vertical lines and their numerical designations are preceded by asterisks (Fig. 2). Table 1 lists the proteins identified in each variant band with $100 \%$ certainty by the Scaffold ${ }^{\mathrm{TM}}$ software, based on the presence of at least 2 peptide sequences identified with certainties of $90 \%$ or more. Also shown is the average \% of the identified protein that was covered by identified peptides and the frequency of the HMW-GS peptides numbered in Fig. 2 in the samples analyzed for each variant. In early experiments, samples were loaded after reduction onto the gels, as usual for analytical gels. In some of these "non-alkylated" samples, peptides from two or three different HMW-GS were found. To rule out that these were from dimers or other multimers between individual subunits that might migrate at positions larger than native 1Dx5, later experiments were performed with proteins that had been alkylated prior to gel loading. In most cases in which both alkylated and non-alkylated samples were analyzed (the four variants in Dx5-F*, the two variants in Dx5 + Dy10-H, the large variant in Dx5 + Dy10-I), there was no difference in the HMW-GS identified. In the cases of Dx5 + Dy10-C and Dx5 + Dy10-A*, fewer different HMW-GS were identified in the alkylated samples than in non-alkylated ones.

MS/MS unambiguously identified the large variants in Dx5-M, Dx5-F*, and Dx5 + Dy10-I as HMW-GS 1Dx5. Every sample that was assigned any protein identity was assigned this identity. Protein coverage ranged from 4.5 to $10 \%$ and both $\mathrm{N}$ - and C-terminal peptides were detected. For the other variants, more than one protein was identified in the majority of samples, but each sample included at least one HMW-GS. Fifteen of 16 samples of the small variant (around $57 \mathrm{kDa}$ ) in event Dx5- $\mathrm{F}^{*}$ contained peptide 5 from $1 \mathrm{Dx} 5$ and many samples contained other $\mathrm{N}$ - and C-terminal peptides. Average coverage was $10 \%$ in the non-alkylated samples. The other proteins identified in these samples can be accounted for by their co-migration in this region of the gels. In particular, globulin 3 was identified in samples from the same gel region of nontransformed 'Bobwhite' (data not shown).

Three different HMW-GS were identified in non-alkylated samples of Dx5 + Dy10-C. All samples contained 1Dx5. The seven alkylated samples had only $1 \mathrm{Dx} 5$. The presence of $1 \mathrm{Dy} 10$ and $1 \mathrm{Bx} 7$ in some of the non-alkylated samples may be due to the presence of HMW-GS dimers or other multimers in this region of the gel. We occasionally found 1Dy10 in this region in lanes containing nonalkylated samples of non-transformed 'Bobwhite' (data not shown).

The larger and smaller variants from event Dx5 + Dy10-H also contained peptides from two different HMW-GS, but these were found in both alkylated and non-alkylated samples. With the exception of one non-alkylated sample of the larger variant, the only peptides from 1Dy10 were from the repeat region: *37, its fragment, and 38 (double-underlined in Fig. 2). N-terminal peptides of $1 \mathrm{Dx} 5$ were found in most of the samples of both variants. Cterminal peptides of $1 \mathrm{Dx} 5$ were found in nearly all the samples of the small variant. The simplest explanation for these findings is that the variants in Dx5 + Dy10-H are chimeric proteins consisting of the $\mathrm{N}$ - and $\mathrm{C}$-terminus of $1 \mathrm{Dx} 5$ and at least part of the repeat region of $1 \mathrm{Dy} 10$.

The variant protein in Dx5 + Dy10-A* migrates more slowly than native 1Bx7 from 'Bobwhite' (lanes 7 and 8 in Fig. 1C) and was found instead of the native protein in segregating $\mathrm{T}_{1}$ seeds. MS/MS identified $1 \mathrm{Bx} 7$ peptides in 3 of 4 non-alkylated samples and 4 of 4 alkylated samples. The presence of $1 \mathrm{Dx} 5$ and $1 \mathrm{Ax} 2 *$ in most of the samples is probably due to contamination of the gel slice with these proteins that migrate nearby. The presence of a version of $1 \mathrm{Bx} 7$ is difficult to explain since the plasmids used to make the transformant encoded 1Dx5 and 1Dy10, not 1Bx7.

The identity of the variant protein in winter wheat lines derived from crosses with event B52a-6 was assigned by comparing results from MS/MS identifications of several protein bands (arrowheads and closed circles in Fig. 1D) in the HMW-GS region of three seeds (lanes 9,11 and 12 in Fig. 1D). Since we did not have the original event for comparison and since these seeds contain potentially comigrating HMW-GS from parents besides 'Bobwhite', it was important to eliminate potentially co-migrating native HMW-GS from consideration. The bands labeled with circles in lanes 9, 11 and 12 of Fig. 1D were identified as containing an Ax (lane 9 only) and a Bx HMW-GS. The peptides detected by MS/MS in these samples do not distinguish between $\mathrm{Ax} 1$ and $\mathrm{Ax} 2^{*}$ or between $\mathrm{Bx} 7$ and $\mathrm{Bx} 17$. However, the positions of the bands in the gels relative to subunits in 'Bobwhite' (BW) and 'Jagger' (J) suggest that the proteins tagged by circles are or include $1 \mathrm{Bx} 17$ in lanes 9 and 12 and $1 \mathrm{Bx} 7$ in lane 11. The band tagged by an arrowhead in lane 9 contains $\mathrm{Ax}-\mathrm{Bx}$ - and y-type HMW-GS. The peptides in two of the samples of this band unambiguously identify 1Dy10, while the peptides in the other two samples do not distinguish between 1By9 and 1Dy10. This band is evidently a mixture of HMW-GS, including Bx7 and the variant protein, which is bigger than but related to 1Dy10. This conclusion is reinforced by the unambiguous identification of the variant band in lane 12 as $1 \mathrm{Dy} 10$ in all four samples. Average protein coverage for these samples is $10.5 \%$ and peptides were identified from both the $\mathrm{N}$ terminus and repeat regions of the native protein.

Peptides 1, 3, 4, 11, 13 and 14 contain cysteine residues conserved in all $\mathrm{x}$-type subunits. The presence of these cysteines in 
A. Dx5 (827 amino acids)

$\frac{\text { EGEASEQLQCERELQELQERELKACQQVMDQQLRDISPECHPVVVSPVAGQYEQQIVVPPK̈GGSFY | PGE }}{1}$ $\frac{T T \text { | PPQQLQQRIFWGI PALLKRYYY SVTCPQQVSYYPGQASPQRPGQGQQPGQGQQGYYPTSPQQPGQW }}{6}$ QQPEQGQPRYYPTSPQQSGQLQQPAQGQQPGQGQQGQQPGQGQPGYYPTSSQLQPGQLQQPAQGQQGQQP Frag 8

GQAQQGQQPGQGQQPGQGQQGQQPGQGQQPGQGQQGQQLGQGQQGYYPTSLQQSGQGQPGYYPTSLQQLG QGQSGYYPTSPQQPGQGQQPGQLQQPAQGQQPGQGQQGQQPGQGQQGQQPGQGQQPGQGQPGYYPTSPQQ SGQGQPGYYPTSSQQPTQSQQPGQGQQGQQVGQGQQAQQPGQGQQPGQGQPGYYPTSPQQSGQGQPGYY | LTSPQQSGQGQQPGQLQQSAQGQK్GQQPGQGQQPGQGQQGQQPGQGQQGQQPGQGQPGYYPTSPQQSGQG * 9 QQPGQWQQPGQGQPGYYPTSPLQPGQGQPGYDPTSPQQPGQGQQPGQLQQPAQGQQGQQLAQGQQGQQPA QVQQGQRPAQGQQGQQPGQGQQGQQLGQGQQGQQPGQGQQGQQPAQGQQGQQPGQGQQGQQPGQGQQGQQ PGQGQQPGQGQPWYYPTSPQESGQGQQPGQWQQPGQGQPGYYLTSPLQLGQGQQGYYPTSLQQPGQGQQP GQWQQSGQGQHWYYPTSPQLSGQGQRPGQWLQPGQGQQGYYPTSPQQPGQGQQLGQWLQPGQGQQGYYPT

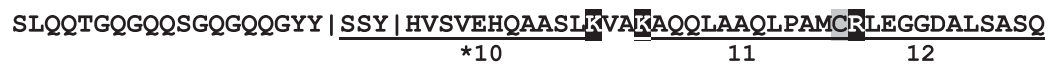

B. Bx7 (774 amino acids)

EGEASGQLQCEHELEACQQVVDQQLRDVSPGCRPITVSPGTRQYEQQPVVPSKAGSFYPSETTPSQQLQQ

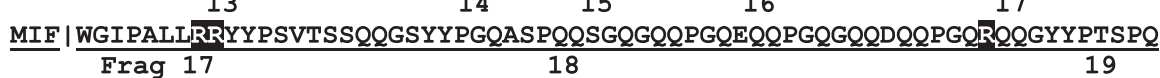
18 19 QPGQGQQLGQGQPGYYPTSQQPGQK̈QQAGQGQQSGQGQQGYYPTSPQQSGQGQQPGQGQPGYYPTSPQQS GQWQQPGQGQQPGQGQQSGQGQQGQQPGQGQRPGQGQQGYYPISPQQPGQGQQSGQGQPGYYPTSLRQPG QWQQPGQGQQPGQGQQGQQPGQGQQSGQGQQGYYPTSLQQPGQGQQLGQGQPGYYPTSQQSEQGQQPGQG KूQPGQGQQGYYPTSPQQSGQGQQLGQGQPGYYPTSPQQSGQGQQSGQGQQGYYPTSPQQSGQGQQPGQGQ SGYFPTSRRQSGQGQQPGQGQQSGQGQQGQQPGQGQQAYYPTSSQQSRQRQQAGQWQRPGQGQPGYYPTS PQQPGQEQQSGQAQQSGQWQLVYYPTS PQQPGQLQQPAQGQQPAQGQQSAQEQQPGQAQQSGQWQLVYYP TSPQQPGQLQQPAQGQQGYYPTSPQQSGQGQQGYYPTSPQQSGQGQQGYYPT I SPQQSGQGQQPGQGQQP R2QGQQGYYPISPQQSGQGQQPGQGQQGYYPTSPQQSGQGQQPGHEQQPGQWLQPGQGQQGYYPTSSQQSG QGHQSGQGQQGYYPTSLWQPGQGQQGYASPYH IVSAEYQAARLEKVAKAQQLAAQLPAMCRLEGSDALSTR 2

*23 $11 \quad 24$

C. Dy10 (627 amino acids)

EGEASRQLQCERELQESSLEACRQVVDQQLAGRLPWSTGLQMRCCQQLRDVSAERCRSVAVSQVARQYEQT VVPPKGGSFYPGETTPLQQLQQGIFWGTSSQ I TVQGYYPGVTSPRQGSYYPGQASPQQPGQGQQPGKWQE $\begin{array}{ccc}32 & \text { Frag } 32 & 33 \\ \text { PGQGQQWYYPT | SLQQPGQGQQIGKGQQGYYPTSLQQPGQGQQGYYPTSLQHTGQRQRPVQGQQPEQGQQ } & \text { SLER }\end{array}$ $34 \quad$ Frag $34 \quad 35$ PGQWQQGYYPTSPQQLGQGQQPRQWQQSGQGQQGHYPTSLQQPGQGQQGHYLASQQQPGQGQQGHYPASQ QQPGQGQQGHYPASQQQPGQGQQGHYPASQQEPGQGQQGQIPASQQQPGQGQQGHYPASLQQPGQGQQGH YPTSLQQL | GQGQQTGQPGQK̈QPPGQGQQTGQGQQPEQEQQPGQGQQGYYPTSLQQPGQGQQQGQGQQGY

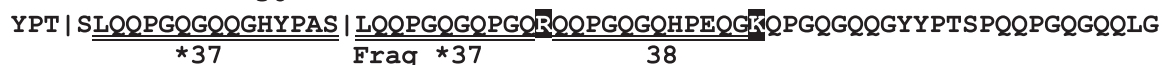
QGQQGYYPTS PQQPGQGQQPGQGQQGHCPTSPQQSGQAQQPGQGQQIGQVQQPGQGQQGYYPTSVQQPGQ GQQSGQGQQSGQGHQPGQGQQSGQEQQGYDSPYHVSAEQQAASPMVAKALQQPATQLPTVCBMEGGDALSA $\underline{\mathrm{SQ}}$ 


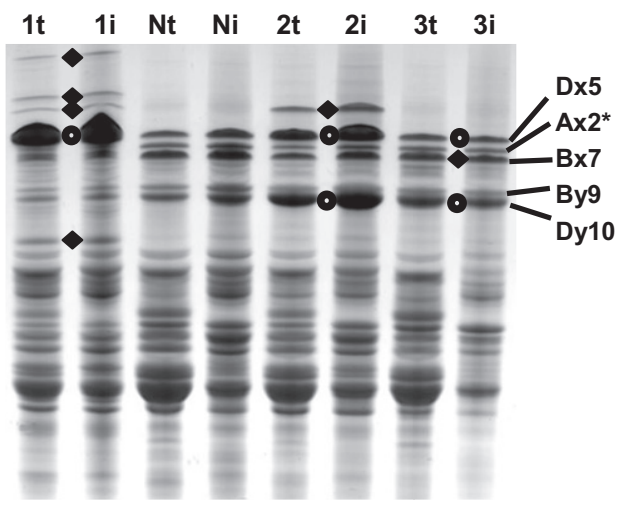

Fig. 3. SDS-PAGE of total seed proteins $(t)$ and those insoluble in $50 \%$ propanol (i) from non-transformed 'Bobwhite' $(\mathrm{N})$ and transgenic lines Dx5-F* (1); Dx5 + Dy10-C (2); and Dx5 + Dy10-A* (3). Diamonds show the positions in adjacent lanes of the variant bands analyzed in this report. Open circles between adjacent lanes indicate the subunits with increased accumulation due to transgene expression. The names and positions of HMW-GS native to 'Bobwhite' are shown to the right. In this gel system, the variant $1 \mathrm{Bx} 7$ subunit in Dx5 + Dy10-A* co-migrates with native $1 \mathrm{Bx} 7$.

the peptides detected by MS/MS predicted that many of the variant proteins containing them would be capable of forming disulfide bonds. To test whether the variants could form inter-molecular disulfide bonds, whole grain flours from homozygous progeny of lines Dx5-F*, Dx5 + Dy10-A* and Dx5 + Dy10-C were extracted with 50\% 1-propanol. SDS-PAGE of the insoluble fractions revealed that both the $1 \mathrm{Dx} 5$ and $1 \mathrm{Bx} 7$ variants were found along with native HMW-GS in the propanol-insoluble fractions (Fig. 3), indicating that they did form inter-molecular disulfide bonds.

\section{Discussion}

We have shown that thirteen novel proteins of unexpected sizes in seven different transgenic lines are versions of HMW-GS (summarized in Table 2). These comprise 3 variants smaller and 10 larger than their related native HMW-GS. Most of the variants we characterized were derived from 1Dx5. One was derived from $1 \mathrm{Dy} 10$ and another appears to be hybrid between the $\mathrm{N}$ - and $\mathrm{C}$-terminus of $1 \mathrm{Dx} 5$ and at least some of the repeat region of 1Dy10. The thirteenth is a variant of $1 \mathrm{Bx} 7$ that accumulated instead of the native version encoded at the Glu-B1 locus.

Other researchers who have transformed wheat with HMW-GS genes have also noted exceptions to the expected expression patterns in transgenic wheat seeds (Alvarez et al., 2000; Barro et al., 1997; He et al., 2005; Vasil et al., 2001). Alvarez et al. (2000) were able to segregate two expression types from their event "F", as we did from our events Dx5-F and Dx5 + Dy10-A. In the former case, the two different types were a co-suppressed line expressing $1 \mathrm{Ax} 1$ and $1 \mathrm{Dx} 5$ transgenes and a non-suppressed line expressing only the $1 \mathrm{Ax} 1$ transgene (Alvarez et al., 2000). Vasil et al. (2001) found two of their nine 'Bobwhite' lines transformed with the gene encoding $1 \mathrm{Ax} 1$ each contained a novel protein larger than the endogenous HMW-GS. Preliminary investigation of this protein by $\mathrm{N}$-terminal sequence analysis revealed similarity to an asparagine synthetase rather than to a HMW-GS.
Table 2

Summary of transgenic events and novel proteins analyzed.

\begin{tabular}{llll}
\hline Event name & $\begin{array}{l}\text { HMW-GS intended } \\
\text { for over-expression }\end{array}$ & $\begin{array}{l}\text { Proteins larger } \\
\text { than expected } \\
\text { and analyzed }\end{array}$ & $\begin{array}{l}\text { Proteins smaller } \\
\text { than expected } \\
\text { and analyzed }\end{array}$ \\
\hline Dx5-M & 1Dx5 & 2 Dx5-like & 1 Dx5-like \\
Dx5-F* & 1Dx5 & 3 Dx5-like & 1 Dx5-like \\
Dx5 + Dy10-H & 1Dx5, 1Dy10 & 1 Dx5/Dy10-like & 1 Dx5/Dy10-like \\
Dx5 + Dy10-I & 1Dx5, 1Dy10 & 1 Dx5-like & None \\
Dx5 + Dy10-C & 1Dx5, 1Dy10 & 1 Dx5-like & None \\
Dx5 + Dy10-A* & 1Dx5, 1Dy10 & 1 Bx7-like & None \\
Dy10 - B52a-6 & 1Dy10 & 1 Dy10-like & None \\
\hline
\end{tabular}

These results are not in agreement with our findings for the novel proteins in our transgenic lines, but the authors emphasized that their data were preliminary (Vasil et al., 2001). They also noted a variant protein in a third transgenic line that co-migrated with $1 \mathrm{Ax} 2 *$ in SDS-PAGE, but did not share its free zone capillary electrophoresis or RP-HPLC mobility (Vasil et al., 2001). Barro et al. (1997) observed novel protein bands of varying sizes in five of the nine transformants they analyzed for expression of $1 \mathrm{Ax} 1$ and $1 \mathrm{Dx} 5$ transgenes. In three of the lines, the novel proteins were recognized by a monoclonal antibody specific for the N-terminal domain of $1 \mathrm{Ax} 1$ and $1 \mathrm{Dx} 5$ subunits. The authors hypothesized that such variants were the products of rearranged HMW-GS genes (Barro et al., 1997).

Despite their large size and the relative scarcity of $\mathrm{R}$ and $\mathrm{K}$ in their repetitive regions, HMW-GS were readily identified by MS/ MS. We were able to assign identities to even faint gel bands. Because of their close relationship, many subunits share some peptides and could not always be distinguished from one another. Some tryptic peptides, particularly those derived from the repetitive regions of the proteins, were not identified because they are smaller or larger than the range detected by MS/MS.

The finding that the variant HMW-GS can form inter-molecular disulfide bonds predicts that their presence will have some influence on the bread-making quality of flours that contain them. However, since they have always been found in transgenic lines that contain additional native subunits, it has not been possible to distinguish the effects of the variants on end-use properties from those due to increases in overall HMW-GS content.

The molecular mechanism for formation of these variants is unknown, but we speculate that the size differences arise mainly from changes in the lengths of the central repetitive coding regions. Such changes are difficult to assess by MS/MS because these regions are large and devoid of the protease cleavage sites commonly used to fragment proteins for MS. The central repetitive domains are known to be subject to length changes during evolution of native HMW-GS genes, perhaps by homologous recombination between misaligned repeated DNA segments (D'Ovidio et al., 1996; Shewry et al., 1989) or by slippage mistakes made by DNA polymerases during replication (Kroutil and Kunkel, 1999). Some of the same mechanisms may be operative during the introduction of DNA into the wheat embryo cells via biolistics. These hypothetical mechanisms predict that larger and/or more regular repeat regions would be more prone to such rearrangements than smaller or less regular repetitive regions. In support of

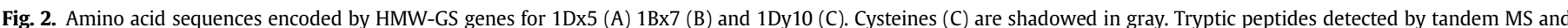

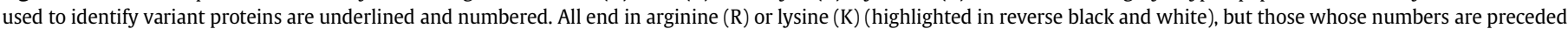

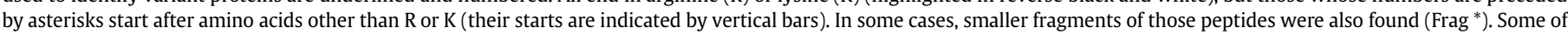

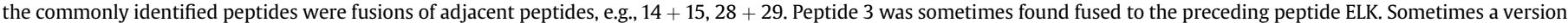

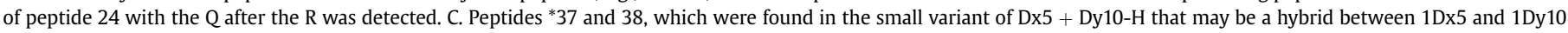
subunits, are double-underlined. 
this prediction, He et al. (2005) found that 2 of 4 lines transformed with a version of the $1 D \times 5$ gene with a $22.5 \%$ longer repeat region contained proteins smaller than would be encoded by the intact coding region in the transforming plasmid. For comparison, we found variants in 3 of 13 transformants bombarded with the natural 1Dx5 gene.

Of particular interest in the work reported here is the $1 \mathrm{Bx} 7$ variant that apparently replaced the native subunit in line Dx5 + Dy10-A* The protein change found in this event suggests that some interaction may have occurred between incoming plasmid DNAs bearing the $1 \mathrm{Dx} 5$ or $1 \mathrm{Dy} 10$ genes and the native $1 B x 7$ gene at the Glu-B1-1 locus. Alvarez et al. (2000) noted the disappearance of the endogenous $1 \mathrm{Ax} 2^{*}$ subunit in two of their six transformed lines. Interestingly, in their line called " $D$ ", there was a novel protein they called " $\mathrm{x}$ " that migrated just below the $1 \mathrm{Bx} 7$ band in their gels. Both $1 \mathrm{Ax}^{*}$ and $\mathrm{x}$ were present in $\mathrm{T}_{1}$ seed extracts, but in $T_{2}$ and $T_{3}$ transgenic segregants, $1 \mathrm{Ax} 2^{*}$ was missing. We speculate that their protein " $x$ " could be a smaller version of $1 \mathrm{Ax} 2^{*}$, generated by a mechanism similar to the one that resulted in a larger version of $1 \mathrm{Bx} 7$ in our line Dx5 + Dy10-A*, and replacing the native $1 A x 2^{*}$ gene on the $1 \mathrm{~A}$ chromosome in some of their segregants.

Some clues to the possible molecular processes at work following biolistic transformation can be found in the structures of the transgene integration sites that result. Because of the complexities of both the insertions and the wheat genome, only a few such transgene integration sites have been analyzed (Abranches et al., 2000; Jackson et al., 2001; Rooke et al., 2003). These studies reveal that genes originally on separate plasmids are cointegrated into the same sites in multiple tandem and nontandem copies, sometimes interspersed with genomic DNA. Rooke et al. (2003) characterized six transgenic wheat lines transformed by biolistics with HMW-GS and selection genes. They found that between one to about 15 copies were clustered in one to three loci, in some cases separated by genomic DNA. Some transgenes were present as tandem repeats and others were rearranged or truncated (Rooke et al., 2003). The interspersion of genomic DNA in transgenes and their truncation and co-integration suggest that incoming DNA is broken and joined together by non-homologous end-joining during the biolistic process. The apparently chimeric Dx5/Dy10 variants found in event Dx5 + Dy10-H could have been formed by such a process. The results of the integration site analyses and the MS/MS data presented here indicate that the incoming plasmid DNA's interact with one another and with genomic DNA before and/or during integration, but the relative roles played by homology-based and non-homologous processes in these interactions is not known.

Regardless of the molecular mechanism, these alterations of HMW-GS genes are quite common during biolistic transformation. As detailed above, they have been documented in several independent laboratories. Three of the events we report here had more than one variant. The proteins we analyzed were clearly visible as individual protein bands in un-crowded regions of 1-dimensional SDS-PAGE gels in seven of 30 transgenic lines. It is possible that other variants could be present in more crowded regions of the gels where they are not readily distinguished from endogenous proteins. Thus, we are probably underestimating the frequency with which such size variants are generated by biolistic transformation. Better separation methods such as RP-HPLC and 2-D electrophoresis might reveal more such variants in our transformants. It is possible that the HMW-GS transgenes are especially prone to such expansion and contraction because there are six closely related genes in each bread wheat cultivar and because they contain long regions of repetitive coding sequence. Whether or not such alterations are common in the coding regions of other genes used in biolistic transformations remains to be investigated.

\section{Conclusions}

Biolistic transformation of wheat with genes encoding HMW-GS often results in changes in their coding regions that lead to production of related proteins larger or smaller in size than the native subunits. In one case, transformation resulted in apparent replacement of the native Glu-B1-1 gene with a version that encoded a larger $1 \mathrm{Bx} 7$ subunit. Such variants are detectable by onedimensional SDS-PAGE in about one-fifth of lines transformed with native genes encoding $1 \mathrm{Dx} 5$ and/or 1Dy10. All the variant proteins were HMW-GS and 6 of 6 tested were found in the polymeric protein fraction. Up to four altered HMW-GS were found in the same transgenic event. The mechanism by which these variants arise requires further investigation.

\section{Acknowledgements}

We thank Jeanie Lin for expert technical assistance. We thank Robert Graybosch and William Hurkman for critical reading of the manuscript. This work was supported by USDA Agricultural Research Service CRIS projects 5325-21430-012-00D and 532543000-028-00D. References to a company and/or product by the USDA are only for purposes of information and do not imply approval or recommendation of the product to the exclusion of others that may also be suitable. USDA is an equal opportunity provider and employer.

\section{References}

Abranches, R., Santos, A.P., Wegel, E., Williams, S., Castilho, A., Christou, P., Shaw, P., Stoger, E., 2000. Widely separated multiple transgene integration sites in wheat chromosomes are brought together at interphase. Plant Journal 24, 713-723.

Altpeter, F., Vasil, V., Srivastava, V., Vasil, I.K., 1996. Integration and expression of the high-molecular-weight glutenin subunit $1 \mathrm{Ax} 1$ gene into wheat. Nature Biotechnology 14, 1155-1159.

Alvarez, M.L., Guelman, S., Halford, N.G., Lustig, S., Reggiardo, M.I., Ryabushkina, N. Shewry, P., Stein, J., Vallejos, R.H., 2000. Silencing of HMW glutenins in transgenic wheat expressing extra HMW subunits. Theoretical and Applied Genetics $100,319-327$.

Alvarez, M.L., Gómez, M., Carrillo, J.M., Vallejos, R.H., 2001. Analysis of dough functionality of flours from transgenic wheat. Molecular Breeding 8, 103-108.

Anderson, O.D., Greene, F.C., Yip, R.E., Halford, N.G., Shewry, P.R., MalpicaRomero, J.-M., 1989. Nucleotide sequence of the two high-molecular-weight glutenin genes from the D-genome of a hexaploid bread wheat, Triticum aestivum L. cv Cheyenne. Nucleic Acids Research 17, 461-462.

Barro, R., Rooke, L., Békés, F., Gras, P., Tatham, A.S., Fido, R., Lazzeri, P.A., Shewry, P.R. Barceló, P., 1997. Transformation of wheat with high-molecular-weight subunit genes results in improved functional properties. Nature Biotechnology 15, 1295-1299.

Barro, F., Barceló, P., Lazzeri, P.A., Shewry, P.R., Ballesteros, J., Martín, A., 2003 Functional properties of flours from field grown transgenic wheat lines expressing the HMW glutenin subunit $1 \mathrm{Ax} 1$ and 1Dx5 genes. Molecular Breeding 12, 223-229.

Blechl, A.E., Anderson, O.D., 1996. Expression of a novel high-molecular-weight glutenin subunit gene in transgenic wheat. Nature Biotechnology 14, 875-879.

Blechl, A., Lin, J., 2007. Expression patterns in transgenic wheats with elevated levels of Dx5 and/or Dy10 glutenin subunits. In: $\mathrm{Ng}$, P., Lookhart, G. (Eds.), Proceedings of the 2006 Gluten Workshop. AACC International, St. Paul, Minnesota, pp. 107-111.

Blechl, A., Lin, J., Nguyen, S., Chan, R., Anderson, O.D., Dupont, F.M., 2007. Transgenic wheats with elevated levels of Dx5 and/or Dy10 high-molecular-weight glutenin subunits yield doughs with increased mixing strength and tolerance. Journal of Cereal Science 45, 172-183.

Craig, R., Beavis, R.C., 2004. TANDEM: matching proteins with tandem mass spectra. Bioinformatics 20, 1466-1467.

D’Ovidio, R., Lafiandra, D., Porceddu, E., 1996. Identification and molecular characterization of a large insertion within the repetitive domain of a high-molecularweight glutenin subunit gene from hexaploid wheat. Theoretical and Applied Genetics 93, 1048-1053.

Darlington, H., Fido, R., Tatham, A.S., Jones, H., Salmon, S.E., Shewry, P.R., 2003 Milling and baking properties of field grown wheat expressing HMW subunit transgenes. Journal of Cereal Science 38, 301-306. 
Görg, A., Weiss, W., Dunn, M.J., 2004. Current two-dimensional electrophoresis technology for proteomics. Proteomics 4, 3665-3685.

Graybosch, R.A., Seabourn, B.W., Chen, Y.R., Blechl, A.E., 2011. Quality and agronomic effects of three high-molecular-weight glutenin subunit transgenic events in winter wheat. Cereal Chemistry 88, 95-102.

He, G.Y., Rooke, L., Steele, S., Békés, F., Gras, P., Tatham, A.S., Fido, R., Barcelo, P., Shewry, P.R., Lazzeri, P., 1999. Transformation of pasta wheat (Triticum turgidum L. var. durum) with high-molecular-weight glutenin subunit genes and modification of dough functionality. Molecular Breeding 5, 377-386.

He, G.Y., Jones, H.D., D’Ovidio, R., Masci, S., Chen, M., West, J., Butow, B. Anderson, O.D., Lazzeri, P., Fido, R., Shewry, P.R., 2005. Expression of an extended HMW subunit in transgenic wheat and the effect on dough mixing properties. Journal of Cereal Science 42, 225-231.

Jackson, S.A., Zhang, P., Chen, W.P., Phillips, R.L., Friebe, B., Muthukrishnan, S., Gill, B.S., 2001. High-resolution structural analysis of biolistic transgene integration into the genome of wheat. Theoretical and Applied Genetics 103, $56-62$.

Keller, A., Nesvizhskii, A.I., Kolker, E., Aebersold, R., 2002. Empirical statistical model to estimate the accuracy of peptide identifications made by MS/MS and database search. Analytical Chemistry 74, 5383-5392.

Kroutil, L.C., Kunkel, T.A., 1999. Deletion errors generated during replication of CAG repeats. Nucleic Acids Research 27, 3481-3486.

León, E., Marín, S., Giménez, M.J., Piston, F., Rodríguez-Quijano, M., Shewry, P.R Barro, F., 2009. Mixing properties and dough functionality of transgenic lines of a commercial wheat cultivar expressing the 1Ax1, 1Dx5 and 1Dy10 HMW glutenin subunit genes. Journal of Cereal Science 49, 148-156.

Nesvizhskii, A.I., Keller, A., Kolker, E., Aebersold, R., 2003. A statistical model for identifying proteins by tandem mass spectrometry. Analytical Chemistry 75, 4646-4658.
Popineau, Y., Deshayes, G., Lefebvre, J., Fido, R., Tatham, A.S., Shewry, P.R., 2001. Prolamin aggregation, gluten viscoelasticity, and mixing properties of transgenic wheat lines expressing $1 \mathrm{Ax}$ and $1 \mathrm{Dx}$ high molecular weight glutenin subunit transgenes. Journal of Agricultural and Food Chemistry 49, 395-401.

Rakszegi, M., Békés, F., Láng, L., Tamás, L., Shewry, P.R., Bedő, Z., 2005. Technological quality of transgenic wheat expressing an increased amount of a HMW glutenin subunit. Journal of Cereal Science 42, 15-23.

Rooke, L., Békés, F., Fido, R., Barro, F., Gras, P., Tatham, A.S., Barcelo, P., Lazzeri, P. Shewry, P.R., 1999. Overexpression of a gluten protein in transgenic wheat results in greatly increased dough strength. Journal of Cereal Science 30, 115120.

Rooke, L., Steele, S.H., Barcelo, P., Shewry, P.R., Lazzeri, P.A., 2003. Transgene inheritance, segregation and expression in bread wheat. Euphytica 129, 301-309.

Shewry, P.R., Halford, N.G., Tatham, A.S., 1989. The high molecular weight subunits of wheat, barley and rye: genetics, molecular biology, chemistry and role in wheat gluten structure and functionality. Oxford Surveys of Plant Molecular and Cell Biology 6, 173-219.

Shewry, P.R., Halford, N.G., Tatham, A.S., Popineau, Y., Lafiandra, D., Belton, P.S. 2003. The high molecular weight subunits of wheat glutenin and their role in determining wheat processing properties. Advances in Food and Nutrition Research 45, 221-302.

Vasil, I.K., Bean, S., Zhao, J., McCluskey, P., Lookhart, G., Zhao, H.-P., Altpeter, F. Vasil, V., 2001. Evaluation of baking properties and gluten protein composition of field grown transgenic wheat lines expressing high molecular weight glutenin gene 1Ax1. Journal of Plant Physiology 158, 521-528.

Vensel, W.H., Tanaka, C.K., Cai, N., Wong, J.H., Buchanan, B.B., Hurkman, W.J., 2005 Developmental changes in the metabolic protein profiles of wheat endosperm. Proteomics 5, 1594-1611. 